\title{
Clinical Decision Support: a 25 Year Retrospective and a 25 Year Vision
}

\author{
B. Middleton ${ }^{1,2}$, D. F. Sittig ${ }^{3}$, A. Wright ${ }^{4}$ \\ 'Apervita, Inc., Chicago, IL, USA \\ 2 Harvard T.H. Chan School of Public Health, Boston, MA, USA \\ ${ }^{3}$ University of Texas Health Science Center at Houston, TX, USA \\ ${ }^{4}$ Brigham and Women's Hospital, Harvard Medical School, Boston, MA, USA
}

\section{Summary}

Objective: The objective of this review is to summarize the state of the art of clinical decision support (CDS) circa 1990, review progress in the 25 year interval from that time, and provide a vision of what CDS might look like 25 years hence, or circa 2040. Method: Informal review of the medical literature with iterative review and discussion among the authors to arrive at six axes (data, knowledge, inference, architecture and technology, implementation and integration, and users) to frame the review and discussion of selected barriers and facilitators to the effective use of CDS.

Result: In each of the six axes, significant progress has been made. Key advances in structuring and encoding standardized data with an increased availability of data, development of knowledge bases for CDS, and improvement of capabilities to share knowledge artifacts, explosion of methods analyzing and inferring from clinical data, evolution of information technologies and architectures to facilitate the broad application of CDS, improvement of methods to implement CDS and integrate CDS into the clinical workflow, and increasing sophistication of the end-user, all have played a role in improving the effective use of CDS in healthcare delivery.

Conclusion: CDS has evolved dramatically over the past 25 years and will likely evolve just as dramatically or more so over the next 25 years. Increasingly, the clinical encounter between a clinician and a patient will be supported by a wide variety of cognitive aides to support diagnosis, treatment, care-coordination, surveillance and prevention, and health maintenance or wellness.

\section{Keywords}

Clinical decision support, electronic health record, health information technology, expert systems, artificial intelligence

Yearb Med Inform 2016;Suppl1:S103-16

http://dx.doi.org/10.15265/IYS-2016-s034

Published online August 2, 2016

\section{Introduction}

In this review of the evolution of Clinical Decision Support (CDS) from 1990 to 2015 we first describe the 'state-of-the-art' for CDS circa 1990, and provide an overview of the key issues of the day. We next describe the evolution that occurred according to six dimensions of technology and implementation practice relevant to CDS: data, knowledge, inference, architecture and technology, implementation and integration, and the evolving end-user. We highlight the barriers and enablers of technology development and effective use of CDS in practice over the past 25 years. Next, we ambitiously describe a potential vision for CDS 25 years hence, and suggest critical issues to monitor the quality of CDS and clinical analytics in the IT-enabled healthcare delivery system.

This paper frames the discussion around CDS defined as follows:

Clinical decision support is a process for enhancing health-related decisions and actions with pertinent, organized, clinical knowledge, and patient information to improve health and healthcare delivery. Information recipients can include patients, clinicians, and others involved in patient care delivery; information delivered can include general clinical knowledge and guidance, intelligently processed patient data, or a mixture of both; and information delivery formats can be drawn from a rich palette of options that includes data and order entry facilitators, filtered data displays, reference information, alerts, and others [1].

Further, CDS has been considered as one component of an over-arching strategy toward widespread and effective use of knowledge in practice, including three essential pillars: 1) best knowledge available when needed, high adoption, and effective use, 2) continuous improvement of knowledge, and 3) CDS methods [2].This would assure that:

Clinical decision support (CDS) provides clinicians, staff, patients, or other individuals with knowledge and person-specific information, intelligently filtered or presented at appropriate times, to enhance health and health care [2].

Fundamentally, CDS is viewed as an essential component of a Learning Health System where a virtuous cycle is created from data generation, to aggregation, analysis, knowledge creation, knowledge dissemination and use, and ongoing measurement for continuous feedback and refinement [3-5]. We subscribe to this belief and suggest that over the next 25 years the use of clinical decision support and a wide variety of cognitive aides will become routine in clinical practice [6].

\section{Evolution of CDS over the Past 25 Years}

\section{State of the Art in CDS in 1990}

In the early 1990's, hospital environments typically had some form of a hospital information system, a variety of departmental information systems [3], and potentially in more advanced settings, applications to support scanned documents, quality reporting, and research applications (often used and maintained outside the traditional "IT" (information technology) department) 
[7]. In ambulatory care environments, penetration of health IT was largely limited to practice management systems to support billing and administrative processes (e.g. scheduling, patient communication). In selected pioneering academic centers and health systems settings, even prior to 1990 , clinical information systems for ambulatory care existed [8-11] as well as a hospital information system (described below). Among these institutions, several began to design, implement, and evaluate more sophisticated clinical decision support capabilities within these systems, in both the inpatient care setting and the ambulatory care environment.

In those early years circa 1990, CDS in hospital care environments was largely limited to those sites developing their own hospital information systems such as the CPRS/Vista effort at the Veteran's Health Administration [12], HELP at the Latter Day Saints (LDS) Hospital [13, 14], the Regenstrief Medical Record System [11], and the Brigham Information and Communication System (BICS) [15]. Some hospitals also were employing vendor-supplied systems from Shared Medical Systems, HBOC, Meditech,TDS/Lockheed Martin, and others as well [16]. Certainly there were other CDS functionalities in hospital environments at the departmental system level - for example in blood banking systems, laboratory information systems, radiation therapy dosimetry systems, ECG interpretation, pulmonary function interpretation, etc. [7]. These pioneering systems developed rich functionality over the intervening years for CDS targeted more directly at the clinician end-user in a wide variety of areas: adverse drug event monitoring [17], drug and parenteral nutrition dosing $[18,19]$, antibiotic prescribing [14], ventilator management [20], report formatting [21], laboratory result alerting [22, 23], blood product ordering [24], infusion pump monitoring [25], quality benchmarking [26], isolation bed management [27], clinical documentation [28-30], diagnostic and therapeutic consultation services [31-34], and more. While it is beyond the scope of this review to detail the CDS functionality of these systems, several key lessons emerged over the early years which are summarized by Bates in the "Ten Commandments" for CDS [35]: speed is everything, anticipate user needs and deliver in real time, fit into the user's workflow, little things can make a big difference (for example 'default' action not being the desired action), physician users resist stopping their workflow, but changing direction is fine (if viewed as valuable), simple interventions work best, ask for additional information from the user only when you really need it, monitor feedback and respond, and lastly actively manage the CDS knowledge base. Further, recognition was growing of the need for more specialized and focused systems and integration of the CDS function into the clinical environment and workflow $[36,37]$. In addition, it was becoming clear that CDS tools needed to be subjected to more rigorous evaluations of their impact on quality and outcomes before they were used in practice, including assessment of cost-effectiveness [38]. As health IT and CDS continue to be more widely implemented and used, these imperatives are still worthy of attention.

\section{Barriers and Limitations}

While these systems had sophisticated CDS functionality in a variety of areas, key barriers and limitations prevented the broad application of such functionality across the industry [39-41]. We identify several themes that effected the development of the use of CDS. First, care reimbursement models that rewarded higher quality care rather than higher volume of care did not exist except in a few cases where the incentives were aligned, such as the Veteran's Health Administration [42], or Kaiser Permanente [43]. Second, the lack of a standardized clinical terminology required system interfaces to have custom and idiosyncratic mappings between systems [44]. Third, information technology was rapidly evolving from mainframe to client-server architectures, and the challenges of upgrading legacy systems were extreme in the midst of a heterogeneous mix of departmental systems, hospital systems, and potentially research data systems [45]. Fourth, despite the sophistication of some of these early CDS applications, it was generally impossible to transfer the knowledge-base used in one application setting to another [46-48]. That is, the logic behind the sophistication of the BICS comput- er order entry (CPOE) drug-dosing algorithm [49] was not readily transferable or portable to another CPOE application, for example a vendor-supplied system (such as Eclipsys). Thus, the considerable task of implementing knowledge in CDS systems had to be tackled at each site. Fifth, as the field of medical informatics was becoming established, there was insufficient workforce development as the number of informatics training programs was very limited [49, 50], and not enough informaticians to manage the translation of evidence into decision support knowledge artifacts. Sixth, the computer literacy of the end-user in clinical care environments, whether physician, nurse, or other allied health professional, or administrative staff, was low as the broad adoption of information technology was just getting underway across the society $[51,52]$. We describe progress on some of these barriers and limitations since the early 1990's in the discussion of the six dimensions of CDS we propose below: data, knowledge, inference, architecture and technology, integration and use, and the end-user. Nevertheless, progress was being made in the design and implementation of CDS systems at some leading sites motivated by academic interest in research and development, desire for higher quality care or lower costs of care. The latter was especially true when institutions had financial responsibility for any part of the 'risk' or costs of care [53]. It is only when the federal incentives for the adoption and meaningful use of health IT were passed that the broad adoption of health IT occurred in the US, with CDS functionality lagging as we discuss below.

\section{Evolving Definition of CDS}

Since the 1990's, we have seen a dramatic evolution in the adoption of health IT (HIT) [54] in the US. With the broad adoption of HIT due to the American Reinvestment and Recovery Act with the Health Information Technology for Economic and Clinical Health (HITECH [55]) component, now nearly all hospitals have certified HIT in place $[56,57]$, and more than $74 \%$ of eligible providers [58] are currently using some form of electronic health record (EHR). This has had the profound effect of making most 
American's health records exist in digital form to a large degree, thus creating much more electronically available data, a platform for health information exchange and data aggregation, and theoretically allowing more decision support to be provided to clinicians in the EMR, and even to patients in patient portal technologies [59-61]. The level of acceptance of CDS among clinicians has also been evolving. The IOM reports "To Err is Human"[62], and "Crossing the Quality Chasm" [63] both acknowledged the frequency of medical errors in practice, and the potential for HIT to ameliorate their incidence and severity. In addition, the explosion of the biomedical knowledge base is also described as a motivation for CDS [64-66], as well as the increasing incidence of diagnostic delay or error [67-70]. There has been only modest growth in CDS however, because the focus has been on HIT adoption and use rather than on truly using it as a platform for care transformation [71]. Nevertheless, CDS is evolving in important ways: the availability of electronic data is increasing $[72,73]$, the knowledge-bases available for CDS from industry are increasing in scope and type to support traditional evidence-based medicine [74, 75], data from electronic health records are being aggregated in interesting ways to support the notion of 'practice-based' evidence to support new forms of inference for CDS [76-81], and commercial electronic medical record (EMR) systems are expanding their CDS capabilities [82, 83]. Further, large data aggregations, or 'big-data', are providing the scale necessary for new forms of discovery via machine learning algorithms [84, 85], association studies [86], and predictive analytics [87-89] to provide both new knowledge for CDS and new forms of CDS [90]. The underlying network, database, and software application technologies are evolving dramatically to facilitate data 'mash-ups' and integration on the fly with graph databases and service-oriented architectures [91-93], and the prototypical use cases for CDS - the types of decisions where CDS can provide cognitive assistance - are evolving dramatically as well. We discuss each of these six dimensions or axes - data, knowledge, inference, architecture, integration, and the end user for CDS in turn below.

\section{Six Key Axes of CDS}

\section{Data}

As touched on above, the amount and types of data coming 'on line' in HIT is staggering [94], yet challenges with the quality and variability of medical data have been understood for some time [95], and electronic record systems may both introduce [96-98] and propagate errors in the record $[68,99-101]$. The decade encompassing this broad adoption of HIT has been called the "Dangerous Decade"[102] because of these potential untoward effects of HIT. Within the acute care or hospital context, IT is now supporting information and process management in nearly every laboratory environment (routine, reference, and research labs), all clinical care environments (from emergency department, to hospital bed, to critical care, to operating room), to long term care settings, and even to the home. Sources of data now include bedside monitoring systems, dietary data, location data (when RFID tags are applied to patient bed, gurneys, wheelchairs, and etc.), and increased administrative and financial data in revenue cycle management systems. Often, these data are aggregated for analytics or 'business intelligence' purposes in large scale data warehouses [72, 103, 104]. With the advent of smart phones, and wearable technologies, new data types are originating also from the patient directly and may provide near continuous monitoring of a wide variety of functions and physiologic parameters, such as number of steps walked, miles run or bicycled, diet, mood, heartrate, hours of sleep, etc. $[105,106]$. Such remote monitoring and the integration of these data in the provider EMR can impact care outcomes and the costs of care [107, 108]. Further, individual 'quantified self' data may be aggregated to allow examination of an individual's social networks, interactions, and behaviors [109]. And further still, the 'open data' movement is making available interesting data sources from the state and federal levels to provide the ability to examine community, environmental, and other public health data as well [110].

Despite the vastly increasing volume and variety of data, however, there still exist significant challenges to seamless interoperability of data [111]. Findings from a January 2016 National Center for Health Statistics (NCHS) Data Brief suggest that approximately one third of physicians are sharing health data with external providers, with a range from a low of $17.7 \%$ (New Jersey) to a high of $58.8 \%$ (North Dakota). Health information exchange and interoperability face several significant financial and technical barriers. First, financial incentives may go frequently against data sharing in the currently predominant fee-for-service business model for healthcare [53, 112]. Second, standardization of data representation at both the terminology and ontology level is incomplete, so data mapping problems may persist and confound health information exchange [113]. Third, not all data of potential interest may be accessible or available on a network backbone of a healthcare delivery system or more generally on the internet in a secure and confidential manner, respecting a patient's privacy and permissions for use [72]. Fourth, when data are aggregated from or exchanged between disparate systems, even within a single healthcare delivery system, or across healthcare delivery organizations, it remains a challenge to ensure that the appropriate matching of records is occurring such that a unique and appropriate patient identity is maintained to preserve data integrity [43, 114, 115]. With HITECH, certified EMR systems needed to demonstrate their ability to exchange a Continuity of Care Document which served as a first step toward improved health information exchange [116]. This work is advancing now with the further development of a more enhanced patient data object - such as the Virtual Medical Record (vMR) (based upon the HL7 Reference Information Model and specifically designed to support decision support) [117-119] and the openEHR [120]. These standards can convey a more detailed set of data and potentially longitudinal data as well. Further, recent work employing an open application programming interface (API) approach has shown promise both for data exchange and innovation [121-123]. Several researchers have described the methods for transforming data into knowledge and insight, and ultimately into CDS [77, 124]. Sittig et al. describe six essential steps in transitioning data through aggregation, analysis, and dissemination, for new research findings from 
comparative effectives research, potentially across multiple sites and disparate EMRs: identification of applicable data within health care transaction systems, extraction to a local data warehouse for staging, modeling of data to enable common representations across multiple health systems, aggregation of data according to this common data model, analysis of data to address research questions, dissemination of study results[124]. These same issues may apply to data and information used in clinical care at the individual or population levels as well. The first two are challenges with finding and creating interfaces to the relevant data itself, the third and fourth are issues of data access and normalization to support analysis, the fifth is an issue of inference, and the sixth may be viewed as analogous to CDS - dissemination of useful findings as decision support interventions. We will discuss the issues of analysis in the knowledge and inference axes for CDS, and the issues of dissemination in the integration and user axes of CDS below.

\section{Knowledge}

In the early 1990's, the variety of CDS available in the pioneering systems such as HELP [125], BICS [15], RMRS, and the CPRS [126] was impressive [11], but it was difficult to share these knowledge artifacts between systems. The Arden Syntax [127, 128] was developed to address this need, at least in part, and allowed the knowledge associated with rule-based systems to be exchanged as "Medical Logic Modules" (MLMs) [129]. The evolution of MLMs was stymied, however, due to the lack of a standardized terminology for clinical concepts (clinical findings, laboratory names, diseases, drugs, etc.). The 'curly braces' type problem arose as MLMs were designed in one setting, and implementation was attempted in another - the facets encoded in MLMs had to be mapped to the local terminology where it was being implemented. Progress was made in improving access to data residing in clinical information systems in two important ways. First, progress was made connecting GELLO (the Guideline Expression Language Object Oriented [130]) to the Arden Syntax to provide a standardized interface and query language for accessing health data from systems
[128]. Significant progress was also made, however, as more robust standards emerged for laboratory terms (Logical Observation Identifiers Names and Codes (LOINC) [131]), diseases (International Classification of Diseases (ICD-9-CM/10), Systematized Nomenclature of Medicine (SNOMED)) and procedures (Current Procedural Terminology (CPT)), drug names (RxNorm [132]), among others. In addition, a considerable body of research focused on effectively representing clinical guidelines developed from evidence review and consensus opinion in a computer-interpretable format - one that would allow a knowledge specification to be developed and shared across disparate clinical information systems [47, 133] (e.g. GuideLine Interchange Format.(GLIF) [134], and computer-interpretable representations of guidelines [135]). This work also lead to experiments in increased knowledge sharing, such as PROFORMA [136], Degel [137], SEBASTIAN [138], the CDS Consortium [139], and others [140-142] (see also architecture and technology axis discussion below). Of particular note is the OpenClinical.org on-line archive of over 600 human-readable information resources on advanced knowledge management methods, technologies, and applications for healthcare [143]. Currently the site serves 300,000 users per year. More recently, the OpenClinical. net website has begun "providing tools and techniques to empower [users] and [their] organizations to share knowledge of best practices in specialist fields, create and publish applications, trial them at the point-of-care, and translate new research into routine services"[144].

The nature and sources of knowledge itself however are changing. The more traditional rule-based knowledge base is rapidly being complemented by knowledge resulting from using data mining techniques for discovery $[145,146]$. With increasing availability of large data sets, association rule mining [86], and other machine learning methods have been employed to discover new forms of knowledge such as gene variant-clinical condition associations [147], novel clinical correlations resulting from surveillance of large data sets [148, 149], and more. Data mining with traditional statistical techniques will help to define clinical algorithms that can be implemented as CDS $[150,151]$. Some would suggest that the knowledge bases of the future will be entirely data driven and not result from consensus opinion such as clinical guidelines, or possibly even from experimental data [6]. Further, text processing techniques are being employed to create large knowledge bases derived from the clinical literature itself (DXplain [152], IBM Watson [153], Isabel [154]). Data mining approaches can be supplemented with ontologies to create sophisticated hybrid knowledge bases $[155,156]$. While these methods are showing promise, we suggest they will need to abide by the same requirements as all CDS systems must: the ability to explain their reasoning [157], show their knowledge and data sources transparently [158], and be able to update as new knowledge (or performance and impact data) arises [5]. We return to these desiderata for CDS at the conclusion of this paper.

\section{Inference}

In the early 1990's and to the current day, the methods of inference used in CDS systems used in practice largely centered on rule-based systems $[159,160]$. While such systems have been shown to have a beneficial clinical impact most often for simple alerts and reminders, they suffer from the difficulty of maintaining the rule knowledge base in an up-to-date format and from potential conflicts between rules. They generally lack the appropriate semantics for different types of knowledge to be represented from a guideline and do not allow for managing uncertainty well - either in the interpretation and encoding of ambiguous statements within a guideline, or in making a recommendation for action to the end user with some sense of certainty of the recommendation [161-164]. In the research setting, with the advent of artificial intelligence methods dating well before 1990 [157], a significant body of work focused on employing other methods for CDS, and there has been an explosion in the development and application of the methods of artificial intelligence to both knowledge discovery and CDS in recent years [165]. CDS was largely developed in one of two paradigms: the rule-based or 
heuristic methods approach, and the probabilistic or Bayesian approach. Early work on differential diagnosis expert systems such as INTERNIST-1[166], QMR [167], DXplain [152], Meditel [168], and others used knowledge-bases crafted by experts and validated on artificial test cases (often drawn from the New England Journal of Medicine Clinicopathologic Conferences). These systems were challenged by terminology and semantics issues on how findings and other patient data were represented, and by inherent limitations in the knowledge-base itself number of disease states or conditions and findings modeled, connections and linkage weights, and heuristic inference methods), and performance was found to be poor [169] - challenges which persist to the present day in heuristic systems. Other efforts built upon the mathematical foundations of CDS [170-173] and focused on Bayesian reasoning such as the system by De Dombal for differential diagnosis of abdominal pain $[174,175]$, or the generalized differential diagnosis of the QMR-DT system [176, 177]. Bayesian reasoning systems are challenged by the difficulty in assessing the conditional probabilities required from experts and by the assumptions that often must be made to simplify the calculation of the posterior probability of diseases [178-180]. For example, De Dombal's system assumed the conditional independence of findings (such as "fever" and "chills"), which are clearly dependent on one another in clinical practice. Failure to acknowledge this conditional dependence may overweight the importance of these findings, just as failure to acknowledge the conditional independence of findings may underweight their importance.

It may be said that we are in the midst of a gradual evolution from the heuristic and rule-based approaches to CDS toward a more numeric-based approach employing machine learning techniques and big data [85]. New machine learning methods such as artificial neural networks - 'deep learning' - combined with the availability of increasingly large clinical data bases are providing new and exciting ways in which patient data can be analyzed to make associations between gene variants and disease states [181], drug - gene variant dependencies (pharmacogenomics [182, 183] and genome-specific drug selection and dosing advice [184, 185]), and the correlations that may be made between a patient state, genomics, behavior, and the environment - broadly described as 'precision medicine' [186, 187].

\section{Architecture and Technology}

We (AW, DFS) described in 2008 a fourphase model for the evolution of clinical decision support systems [188]. The phases describe the evolution from standalone decision support systems, decision support integrated into clinical systems, the emergence of standards for sharing clinical decision support content, and web service models for decision support. The four-phase model traces the evolution of CDS architectures and integration approaches [188], and parallels to a degree the evolution of information technology and networking. The first CDS systems, such as Warner's congenital heart disease diagnostic system [189], Bleich's acid-base system [190], and De Dombal's abdominal pain advisor [174] were all standalone - their users had to access the systems through their own front-end interface and enter data about the patient under consideration. Typically, these systems were accessed via early time-sharing protocols from mainframe implementations. In the early 1990's, many researchers working on CDS were beginning to understand that the so-called "Greek oracle model" of CDS was not going to work [191]. Briefly, this model most often involved a standalone computer system that generated a list of questions or requests for data which the clinician entered (e.g., Shortliffe's Mycin was one of the earliest examples of such a system [192]), and had little integration with the EHR. The computer then generated a rank ordered list of potential answers (often diagnoses). Even though the evaluation of many of these systems demonstrated a high degree of accuracy [193], they were not adopted by clinicians for the routine care of patients for many reasons including the following: first, they were not integrated into the clinicians' data entry or review workflows which required clinicians to first recognize that they had a knowledge deficit which is still uncommonly difficult [194], and required the clinician user to enter a long list of data or findings using the semantics and terminology of the system; second, the knowledge bases were incomplete and difficult to maintain which resulted in ungraceful degradation of performance on cases outside of the system's area of expertise. Third, making an accurate diagnosis in a difficult case was one of the most professionally satisfying activities clinicians engaged in and they were not ready or willing to give that activity up. Fourth, we hold computers to a higher standard than humans. Such systems were expected to be (or believed to be) accurate, and had difficulty describing a degree of certainty in anything other than probabilistic terms, or simply summarizing findings for and against a diagnostic hypothesis. Humans are much better at expressing uncertainty than computers.

As hardware and network technologies evolved from mainframe toward client-server architectures, and ultimately n-tier web services, CDS architectural design evolved as well. A few years after the advent of stand-alone CDS systems, the first efforts to integrate CDS into clinical information systems started with the HELP system [195] at LDS Hospital. HELP brought CDS directly into the end-user clinician workflow, and was followed shortly by the Regenstrief Medical Record System (RMRS) [11], the Brigham Integrated Computer System (BICS) at Brigham and Women's Hospital $[15,196]$, and the VA's Computerized Patient Record System (CPRS) [197-199]. In part, this evolution was facilitated technically by the move from time-sharing sessions with mainframe-based applications toward context sharing and management. With the advent of the HL7 Common Context Object Workgroup (CCOW) and CCOW standard [200] ratified in April 1999, applications could securely pass patient and user context, thus allowing a user to access an array of applications after logging on to a single application [201]. Despite the significance of this advance, the user still had the experience of using multiple applications.

As the second phase of EHR-integrated CDS systems took hold[16], it became clear that sharing the knowledge embedded within CDS systems across sites would be valuable. To support this, the Arden Syntax was developed in $1989[129,202,203]$ by combining 
related elements of the RMRS and HELP system syntaxes and standardizing them, launching a third phase of standards-based approaches for encoding and sharing clinical knowledge. Since 2005, in the third phase of CDS, a number of new initiatives have been started which focused on sharing CDS content through web services rather than by moving knowledge artifacts around, and this trend is paralleled in the emerging consumer space of mobile health applications found on smart phones. Both take advantage of more robust standards for connectivity and communication between application servers on a network backbone.

In the fourth phase of CDS, EHRs are connected to CDS services, passing patient data and receiving inferences back. SEBASTIAN [138] and SAGE [204, 205] were the first examples of service-oriented CDS, followed by SANDS [93]. The AHRQ-funded Clinical Decision Support Consortium (CDSC) conducted a large demonstration of service-oriented CDS, using the Continuity of Care Document standard to exchange patient data at four sites across the US: Partners HealthCare, the Regenstrief Institute, the Robert Wood Johnson Medical School, and the WVP Health Authority [91, 206-209]. The same technology stack was also successfully employed in a large demonstration of clinical decision support for imaging in the context of pediatric traumatic brain injury [210]. The OpenCDS initiative is now working on a set of open source CDS tools to support sharing of CDS via services as well [211]. The MobiGuide project, funded by the European Union, is a notable patient-oriented decision support tool that makes extensive use of decision support [212, 213].

Mirroring the third and fourth phases of CDS, the US Office of the National Coordinator for Health Information Technology (ONC) started the Health-e-Decisions (HeD) initiative as part of the Standards and Interoperability Framework. HeD developed two use cases: the first, CDS Artifact Sharing corresponded to the third phase of this CDS model, and the second use case, CDS Guidance Service, corresponded to the fourth phase of CDS. At this time, adoption of the HeD schemas and standards has not been widespread, but may increase over time. Parallel development and extensions to technologies for patient-matching [114], patient and end-user context management [214], secure authorization, authentication, and device security technologies will also contribute to the success of this web-services enabled fourth phase of CDS, hopefully through standardized APIs [121, 122]. Some would suggest that a fully modular approach may allow more innovation to occur in and around EMRs [215], and create an 'app store' model for a substitutable applications approach to health IT [216, 217]. We anticipate that, as CDS becomes more complex, service-oriented integration of CDS will become more prevalent, potentially through a substitutable component architecture, allowing separation of knowledge and inference from the presenting EHR (or whichever technology layer) but still permitting deep workflow integration. As semantics become more standardized in EHRs for reasons of interoperability, we also anticipate that CDS sharing will become more straightforward.

\section{Implementation and Integration}

Since 1990, there has been a dramatic evolution of how CDS may be integrated into the clinician's workflow in a growing variety of application frameworks and technology contexts. Despite these advances, a central problem arises from the extraordinary variability in clinical practice patterns [218] and clinical workflows. Given this variation, it is no surprise that many clinicians view CDS as arising at an inopportune time in their workflow [219, 220], and many CDS alerts are simply ignored or overridden [221-224]. Over the past 25 years, most CDS researchers turned away from developing complex CDS systems and turned their attention to the development of what one of us (DFS) termed "mediocre systems designed to keep doctors from making silly mistakes". Thus was born the CDS age of "alerts and reminders", which were more amenable to integration into EHR systems and the clinician's workflow. Briefly, these interventions, originally conceived by McDonald et al. in the 1970's, were designed to provide a safety net for clinicians, who had inadvertently forgotten or missed a key data element [225]. While seemingly a win-win situation for both clinicians and CDS developers in the vast majority of cases, the CDS recommendations were not helpful, as evidenced by unacceptably high override rates [226] for a variety of reasons including: outdated patient data, missing patient data, CDS logic that did not precisely fit the patient, clinically irrelevant alerts such as drug-food alerts, or CDS that came at a point in the clinician's reasoning about the patient that was too late (decision already made). In theory, automated CDS integrated into the clinicians' workflow at the point of care is one of the main benefits associated with EHRs, and this has been successfully accomplished for Infobuttons [227-229], order sets [230, 231], documentation templates [232-234], data displays/flowsheets, as well as alerts and reminders. Based on the current unacceptably high rate of clinician overrides of these CDS suggestions, however, it is clear that in practice CDS has not achieved anywhere near its potential and significant barriers persist. Thus, a central challenge is both defining and standardizing clinical workflows such that useful and reliable insertion points could be defined in the clinical workflow - implying, of course, standardized care pathways or protocols which is to a large degree at odds with the idiosyncrasies that may arise with the care of individual patients. This need for tight integration of CDS interventions with EHRs has been one of the key driving forces in the evolution of CDS over the last 25 years [196].

Major factors in the current dissatisfaction with CDS include the following: first, the difficulty in aligning the CDS with the clinician user's mental model of the patient and potential diagnostic or therapeutic interventions [235], second, the difficulty in developing, maintaining, and integrating the clinical logic required to generate accurate, patient-specific, clinical suggestions[83, 236-238], third, the difficulty in gathering and assessing the quality of the data upon which this logic acts [100, 239, 240], and lastly, the rapid evolution of technology platforms as described above - clinician end-users now may be accessing patient records via a desktop application, a handheld application, or via a web-interface on a variety of devices, which implies significant technology and implementation challenges.

If we can overcome the difficulties involved in integrating CDS interventions 
within EHRs, then we can begin to achieve the tremendous improvements in patient safety, healthcare quality, and efficiency promised by the HITECH policy initiatives and demonstrated at leading sites. We suggest that CDS will be less intrusive in the future and more of a background function to support the cognitive activities of the user. We describe this further in our vision for CDS 2040.

\section{Users}

Over the last 25 years, the field of clinical informatics has witnessed an evolution in the nature and type of users of clinical decision support systems, and the types of cognitive support that these systems may provide. The first change was in the nature of its users themselves, which is best explained by Rogers' diffusion of innovations theory [241]. For example, in the early 1990's clinical decision support users were what Rogers' would term "innovators". These clinicians were extremely interested in experimenting with this new technology and willing to put up with its limitations [14]. They reveled in the fact that they were on the "cutting edge" and downplayed any problems with the systems they were using, and some of the early evaluations of such systems by the very same people, who were designing, implementing, and using them, may be biased [159, 242, 243]. More recently, as clinical decision support has become more mainstream, the majority of its users are "late majority" or even "laggards", who are less interested in the technology and more interested in doing the work that the technology was designed to help them with. They are much more critical of existing system limitations and less willing to put up with less than stellar performance [224]. As Friedman recognized in developing the "fundamental theorem of informatics", which postulates that "a person working in partnership with an information resource is "better" than that same person unassisted", CDS interventions should be most useful to clinicians, and potentially even patients, with less academic training and clinical experience [244]. Over the years, this concept has been used to implement CDS interventions specifically designed for respiratory therapists
[20], nurses [245], and even patients [246, 247] with excellent results.

\section{Summary of Key Disruptions, Barriers, Accelerators}

Reflecting on the six dimensions of CDS discussed above, several themes are observed which adversely impact the effective implementation and use of CDS in clinical practice, and certain developments which may accelerate its use. We summarize these using the 'people, process, and technology' framework first elaborated by Lorenzi [248].

\section{People}

First, the end user needs to recognize an information or knowledge deficiency before he may appreciate the value of a CDS system. Similarly, the end-user should have a clear understanding of the right questions to ask CDS. The CDS system must provide guidance in a consistent manner, however, coherent with the user's mental model of the patient, processes, or the context of care and decision-making. The user must be facile with information technology of course, and should understand its limitations. As information technology becomes more ubiquitous in almost every dimension of modern life, end-users are becoming much more sophisticated with health IT as well: as we rapidly become accustomed to using decision support in our daily lives for getting directions, assessing the weather, managing finances, and the many ways in which modern smart phones for example can assist in communicating, scheduling, and accessing information, it is highly probable that people will become more adept to the use of CDS.

\section{Process}

Managing the process of knowledge translation, specification, and implementation of CDS represents perhaps a larger hurdle to overcome than simply using modern IT. The methods for discovery of new knowledge are rapidly evolving, and the fruits of 'big data' analysis and machine learning are producing new insights at an ever increasing pace. Nevertheless, new knowledge must be care- fully vetted before implemented and used routinely in CDS, and it must be subjected to a transparent and formalized knowledge management processes to ensure its accuracy, currency, and appropriateness for CDS [237]. By the same token, however, IT may enable more novel forms of knowledge engineering and management exploiting virtual collaboration technologies [249, 250]. Large scale knowledge-engineering efforts remain difficult, and it still essentially impossible to share knowledge artifacts between information systems (except in innovative research settings). This burden of knowledge engineering and management may be the largest obstacle to overcome, but progress is being made, and the potential impact remains huge. As healthcare moves toward a value-based reimbursement system, the need to effectively share best-practices to improve the quality of care, and lower the costs of care, may be the strongest driver yet for the implementation and effective use of CDS.

\section{Technology}

The ongoing and dramatic evolution of technology is at once both the greatest enabler of change in technology-dependent human endeavors, and one of the most significant hurdles to overcome. As an enabler, technology is evolving to put unprecedented capabilities into the hands of the end-user whether it is accessing the world's information via simple and convenient web interfaces or mobile applications - via keyboard or voice interactions, to accessing extremely sophisticated cognitive aides and other tools that can be applied to reasoning both in every-day activities, as well as complex clinical decision support. As a barrier, this same rapid evolution of technology incurs a 'technology debt' where new systems must typically account for the installed base of legacy systems, and chart an evolutionary path for new features and functions. Occasionally, there may be a dramatic paradigm shift when new technology is introduced into a previously unaddressed space, such as the advent of smart phone technologies and mobile applications. Another dimension of rapid evolution in technology is the ever increasing amount of data coming online in electronic form. As standards for exchange and aggre- 
gation of these data improve, new and vast aggregations of data may be created and subjected to analysis. The rapid evolution of new methods for machine learning from big data is an important part of this technology evolution given the novel data architectures that are being created to support it and their new technology platforms.

In summary, we suggest that the evolution and increased use of CDS in practice is inevitable given the explosion of biomedical knowledge, and the pressure to improve quality and lower costs in value-based care. However, further work needs to be done on standardizing methods for knowledge and data representation, CDS implementation in clinical care environments (standardized workflow insertion points), and patient data and knowledge exchange.

\section{CDS: The Next 25 Years}

We are in the midst of a dramatic and fundamental transition of the human condition given the exploding power of computing, connectivity between man and machine, connectivity between machines, nearly ubiquitous information access, and the accelerating speed of data production and aggregation, and knowledge discovery. The impact on society has been profound and there is likely to be no attenuation in this rate of change in the near term - if anything it may accelerate. While information technology is dramatically impacting the manner in which both business and social interactions occur in many sectors, healthcare has been lagging but may be quickly catching up. The implications of these changes directly impact the fundamental nature of reasoning and inference [251-253], investigation and discovery [6, 254-256], knowledge engineering and management $[257,258]$, and drive the predictive analytics, algorithms, and artificial intelligence that increasingly underlie nearly every stage of decision-making $[2,161,259,260]$.

In 2040, we will likely be in an era not only of ubiquitous computing, and the implied ubiquitous access and availability of online information and knowledge, but also have the ubiquitous availability of extraordinarily powerful cognitive aides which may support, and in some cases supplant, human reasoning [165]. We will likely have cognitive aides with which both clinicians and patients can interact with verbally, and when necessary visually, for example in augmented reality environments. We will have massive data streams resulting from pervasive monitoring and interactions with personal health monitors, the environment, and related public health data, as well as an improved understanding and monitoring of the genome, metabolome, proteome, and microbiome. This implies the very nature of knowledge, and reasoning or decision-making, are changing under our feet. The advent of the World Wide Web has made information access trivial anytime and anywhere, and by a variety of devices [261] - perhaps one day we will have direct access from our brains via a neural conduit! Critical questions must be asked about how one could still reason in this new world, what is a realistic expectation for the clinician's knowledge base [64], how do we perform complex inferences in light of patient preferences and societal norms [262], and how do we manage reasoning under uncertainty? On Scott Blois' 'cognitive funnel' [263] we must ask what is the optimal role of the human, the machine aided or enhanced human, and the autonomous machine in his cognitive funnel, or decision-making in healthcare?

The most critical evolution over the next 25 years for CDS will be the discovery and use of methods for collating clinical knowledge in any form - facts, relationships, terminologies, ontologies - and make it evolve through a process of continuous feedback and improvement, whether from pragmatic experience in clinical care, crowd sourcing and updating, or machine learning. The growth of semantic graph database technologies will lead to new inferential capabilities, distinct from traditional approaches. While information access is becoming trivial, the organization and collation of information into actionable knowledge is not - the need for a new taxonomy of disease based upon our improved understanding of the genomic basis of disease, and the influences of disorders of translation and expression, behavior, community, and environment has been described in a recent National Research Council Report[187].
Future inference methods will take advantage of a 'knowledge commons' describing and interrelating a wide array of knowledge artifacts at multiple levels of inference, and allow inferences and decision support to be made from the genomic level to the community or population level [187]. Clinical reasoning will increasingly be conducted in a shared decision-making paradigm [264] but in a three-way interaction including patient, provider, and a cognitive aide or "AI", and the importance of patient preferences and utilities will increase. The importance of codified knowledge based upon a new taxonomy of disease will grow as we increasingly see the use of artificial intelligence, algorithms, neural nets, and other means of inference assist both the clinician and the patient in decision-making.

The impact and value of CDS in precision medicine will be significant. With the advent of 'big data', and rapid advances in gene sequencing and association with disease, rapid changes are occurring also in the ability to discover new gene variant - disease associations [147, 265, 266], and interactions between the genome and the exposome [6]. We can now conduct in silico experiments from the molecular and proteomic level, to the organismic and population level - to predict clinical outcomes with advanced analytics, and to empower the patient himself with tools that facilitate self-management of health and disease [267-270]. Highly detailed models, algorithms, and simulations will be run continuously on the patient's behalf to support the clinical reasoning of the provider, and care team, in conjunction with the patient or a patient proxy [6].

If we can codify and preserve useful knowledge, and learn how best to share and disseminate useful findings rather than re-discover repeatedly what we already know [271], we may witness an acceleration of learning and the adoption of best practices across the continuum of care [65]. Critical attention must be paid, however, to ensure that informatics and data science methods underlying these investigations and the new tools continue to critically assess the quality of the evidence in decision-making at any level, the relevance of decision-making for the patient at hand, and assess the efficacy and impact in each and 
every case to drive a Learning Health System $[4,66]$. We suggest that all CDS systems of any form and at any level (genomic, proteomic, metabolomic, organismic, population, or environmental) be able to provide a rationale or explanation to the end-user for the recommendation proposed with an assessment of certainty or confidence in the recommendation, describe the data and knowledge sources and the reasoning model they use, update the inference methods as necessary, and monitor their impact and learn from experience. These desiderata for CDS will help assure the safe and effective use, transparency, and ongoing refinement of these tools. Achieving the vision of precision medicine [150] and the learning health system will not only depend upon a continuous development and refinement of our understanding of disease, but also upon the elaboration of predictive analytics and cognitive aides across the translational spectrum and continuum of care[272-275]. This process should leverage available online electronic data from EMRs, PHRs, wearable technologies, clinical investigations, and the growing body of relevant data from all other sectors of society: behavioral data, environmental data, public health, and social and community data, and entitle patients to access and use their data as they wish [276].

\section{Conclusion}

We close this review by anticipating with excitement the advances in clinical reasoning that will come, for clinicians and for machines, and we anticipate the benefits which will accrue for our patients, ourselves, and society at large. We foresee an inevitable evolution in the nature of clinical practice, and in what the clinician is expected to know, and do. Analogously, we see an evolution in what the patient is expected to know, and do, given the increasing availability of cognitive aides directed toward the consumer of health care. Nevertheless, we believe that the power of human reasoning will never be fully supplanted by an algorithm of any kind, nor do we believe the intimate and essential relationship between a doctor and her patient can be replaced by a computer.

\section{References}

1. Osheroff JA, Teich JM, Levick DL, Saldana L, Velasco FT, Sittig DF, et al. Improving Outcomes with Clinical Decision Support: An Implementer's Guide, 2nd ed., Healthcare Information and Management Systems Society, Chicago, IL; 2012.

2. Osheroff JA, Teich JM, Middleton B, Steen EB, Wright A, Detmer DE. A roadmap for national action on clinical decision support. J Am Med Inform Assoc 2007;14:141-5.

3. Henry SB, Lenert L, Middleton B, Partridge R. Linking process and outcome with an integrated clinical information management system. Proc HIMSS 1993;7:81-93.

4. Friedman CP, Wong AK, Blumenthal D. Achieving a nationwide learning health system, Sci Transl Med 2010;2:1-3.

5. Etheredge LM. A rapid-learning health system. Health Aff (Millwood) 2007:26:w107-18.

6. Kohane IS, Drazen JM, Campion EW. A Glimpse of the Next 100 Years in Medicine. N Eng J Med 2012;367:2538-9.

7. Maviglia SM, Kuperman GJ, Middleton B Hospital Information Systems, Hospital Medicine. Philadelphia: Lippincott; 2005.

8. Barnett GO, Justice NS, Somand ME, Adams JB, Waxman BD, Beaman PD, et al. COSTAR; A computer-based medical information system for ambulatory care. Proc IEEE 1979;67:1226-37.

9. McDonald CJ, Murray R, Jeris D, Bhargava B, Seeger J, Blevins L. A computer-based record and clinical monitoring system for ambulatory care. Am J Public Health. 1977;67:240-5.

10. Middleton B, Renner K, Leavitt M. Ambulatory practice clinical information management: problems and prospects. Proc HIMSS 1997;11:97-112.

11. McDonald CJ, Overhage JM, Tierney WM, Dexter PR, Martin DK, Suico JG, et al. The Regenstrief Medical Record System: a quarter century experience. Int J Med Inform 1999;54:225-53.

12. Brown SH, Lincoln MJ, Groen PJ, Kolodner RM VistA--U.S. Department of Veterans Affairs national-scale HIS. Int J Med Inform 2003;69;135-56.

13. Sittig DF, Pace NL, Gardner RM, Beck E, Morris $\mathrm{AH}$. Implementation of a computerized patient advice system using the HELP clinical information system. Comp Biomed Res 1989;22:474-87.

14. Evans RS, Pestotnik SL, Classen DC, ClemmerTP, Weaver LK, J.F. Orme JF, et al. A computer-assisted management program for antibiotics and other antiinfective agents. N Eng J Med 1998;338:232-8.

15. Teich JM, Glaser JP, Beckley RF, Aranow M, Bates DW, G.J. Kuperman GJ, et al. The Brigham integrated computing system (BICS): advanced clinical systems in an academic hospital environment. Int J Med Inform 1999:54:197-208.

16. Davides C. Health Care Information Technology Family Tree: Healthcare Technology Consolidation 1992-2014. HISTALK2.com. http://histalk. com/download/HCIT_ConsolidationChart.pdf. Accessed February 12, 2016.

17. Bates DW, Teich JM, Lee J, Seger D, Kuperman GJ, Ma'Luf N, et al. The impact of computerized physician order entry on medication error prevention. J Am Med Inform Assoc 1999;6:313-21.
18. Nielsen AL, Henriksen DP, Marinakis C, Hellebek A, Birn H, Nybo M, et al. Drug dosing in patients with renal insufficiency in a hospital setting using electronic prescribing and automated reporting of estimated glomerular filtration rate. Basic Clin Pharmacol Toxicol 2014;114:407-13.

19. Lehmann CU, Conner KG, Cox JM. Preventing provider errors: online total parenteral nutrition calculator. Pediatrics 2004:748-53.

20. Sittig DF, Gardner RM, Morris AH, Wallace CJ. Clinical evaluation of computer-based respiratory care algorithms. Int J Clin Monit Comput 1990; 7:177-85.

21. Rennels GD, Shortliffe EH, Stockdale FE, Miller PL. A computational model of reasoning from the clinical literature. Comput Methods Programs Biomed 1987:24:139-49.

22. Kuperman GJ, Teich JM, Bates DW, Hiltz FL, Hurley JM, Lee RY, et al. Detecting alerts, notifying the physician, and offering action items: a comprehensive alerting system Proc AMIA Annu Fall Symp 1996:704-8.

23. Samal L, Stavroudis TA, Lehmann CU, Miller RE, Lehmann H. Effect of a laboratory result pager on provider behavior in a neonatal intensive care unit. Proc AMIA Annu Fall Symp 2008:1121.

24. Hibbs SP, Nielsen ND, Brunskill S, Doree C, Yazer MH, Kaufman RM, et al. The impact of electronic decision support on transfusion practice: a systematic review. Transfus Med Rev 2015;29:14-23.

25. Manrique-Rodríguez S, Sánchez-Galindo A, Fernández-Llamazares CM, López-Herce J, Echarri-Martínez L, Escudero-Vilaplana V, et al. Smart pump alerts: all that glitters is not gold. Int J Med Inform 2012;81:344-50.

26. Ricciardi TN, Masarie FE, Middleton B. Clinical benchmarking enabled by the digital health record. Stud Health Technol Inform 2001;84:675-9.

27. Schmidt R, Geisler S, Spreckelsen C. Decision support for hospital bed management using adaptable individual length of stay estimations and shared resources. BMC Med Inform Decis Mak 2013;13;3.

28. Michael Fitzmaurice J. Three Decades of Research on Computer Applications in Health Care: Medical Informatics Support at the Agency for Healthcare Research and Quality. J Am Med Inform Assoc 2002:9:144-60

29. Tang PC, LaRosa MP, Gorden SM. Use of computer-based records, completeness of documentation, and appropriateness of documented clinical decisions. J Am Med Inform Assoc 1999;6:245-51.

30. Embi PJ, Yackel TR, Logan JR, Bowen JL, Cooney TG, P.N. Gorman PN. Impacts of computerized physician documentation in a teaching hospital: perceptions of faculty and resident physicians. J Am Med Inform Assoc 2004;11:300-9.

31. Bankowitz RA, McNeil MA, Challinor SM, Parker RC, Kapoor WN, Miller RA. A computer-assisted medical diagnostic consultation service. Implementation and prospective evaluation of a prototype. Ann Intern Med 1989;110:824-32.

32. First MB, Soffer LJ, Miller RA. QUICK (QUick Index to Caduceus Knowledge): Using the Internist-1/Caduceus knowledge base as an electronic textbook of medicine. Comp Biomed Res 1985;18:137-65

33. Rennels GD, Shortliffe EH, Stockdale FE, Miller 
PL. A Computational Model of Reasoning from the Clinical Literature. AI Magazine 1989;10:49.

34. Miller RA Medical diagnostic decision support systems--past, present, and future: a threaded bibliography and brief commentary. J Am Med Inform Assoc 1994;1:8-27.

35. Bates DW, Kuperman GJ, Wang S, Gandhi T, Kittler A, Volk L, et al. Ten commandments for effective clinical decision support: making the practice of evidence-based medicine a reality. J Am Med Inform Assoc 2003;10:523-30.

36. Mitchell E, Sullivan F. A descriptive feast but an evaluative famine: systematic review of published articles on primary care computing during 198097. BMJ 2001;322:279-82.

37. Liu J, Wyatt JC, Altman DG. Decision tools in health care: focus on the problem, not the solution, BMC Med Inform Decis Mak 2006;6;4.

38. Wyatt JC, Wyatt SM. When and how to evaluate health information systems? Int J Med Inform 2003;69:251-9.

39. Linder JA, Schnipper JL, Tsurikova R, Melnikas AJ, Volk LA, Middleton B. Barriers to electronic health record use during patient visits. Proc AMIA Annu Fall Symp 2006:499-503.

40. Heathfield H, Pitty D, Hanka R. Evaluating information technology in health care: barriers and challenges. BMJ 1998;316:1959-61.

41. Poon EG, Blumenthal D, Jaggi T, Honour MM, Bates DW, Kaushal R. Overcoming the barriers to the implementing computerized physician order entry systems in US hospitals: perspectives from senior management. Proc AMIA Annu Fall Symp 2003:975.

42. Kizer KW, Fonseca ML, Long LM. The veterans healthcare system: preparing for the twenty-first century, Hosp Health Serv Adm 1997:42:283-98.

43. Middleton B. Accelerating U.S. EHR Adoption: How to Get There From Here. Recommendations Based on the 2004 ACMI Retreat. J Am Med Inform Assoc 2004;12:13-9.

44. Masarie FE, Miller RA, Bouhaddou O, Giuse NB, Warner HR. An interlingua for electronic interchange of medical information: Using frames to map between clinical vocabularies, Comp Biomed Res 1991;24:379-400.

45. Haux R. Health information systems - past, present, future. Int J Med Inform 2006;75:268-81.

46. Elkin PL, Peleg M, Lacson R, Bernstam E, Tu S, Boxwala $A$, et al. Toward the standardization of electronic guidelines. JAMA 2000;17:39-44.

47. Sonnenberg FA, Hagerty CG. Computer-interpretable clinical practice guidelines. Where are we and where are we going ? Yearb Med Inform 2006:145-58.

48. Miller RA. Computer-assisted diagnostic decision support: history, challenges, and possible paths forward. Adv Health Sci Educ Theory Pract 2009;14 Suppl 1:89-106.

49. Chertow,GM Lee J, Kuperman GJ, Burdick E, Horsky J, Seger DL, et al., Guided medication dosing for inpatients with renal insufficiency, JAMA. 2001;286:2839-44.

50. Lorenzi N, Bloomrosen M. Accelerating the deployment of a health information technology and informatics workforce through education, training, research, and evaluation. Stud Health Technol Inform 2011;170:113-21.
51. Kulikowski CA, Shortliffe EH, Currie LM, Elkin PL, Hunter LE, Johnson TR, et al. AMIA Board white paper: definition of biomedical informatics and specification of core competencies for graduate education in the discipline. J Am Med Inform Assoc 2012;19:931-8.

52. Vedel I, Lapointe L, Lussier M-T, Richard C, Goudreau J, Lalonde L, et al. Healthcare professionals' adoption and use of a clinical information system (CIS) in primary care: Insights from the Da Vinci study. Int J Med Inform 2012;81:73-87.

53. Institute of Medicine, Health IT and Patient Safety: Building Safer Systems for Better Care. Washington D.C.:The National Academies Press, Washington; year?

54. Middleton B. Achieving U.S. Health information technology adoption: the need for a third hand. Health Aff (Milwood) 2005;24:1269-72.

55. Blumenthal D, Glaser JP. Information technology comes to medicine. N Eng J Med 2007;356:2527-34.

56. Blumenthal D. Launching HITECH. N Eng J Med 2010;362:382-5.

57. Adler-Milstein J, DesRoches CM, Furukawa MF, Worzala C, Charles D, Kralovec P, et al. More than half of US hospitals have at least a basic EHR, but stage 2 criteria remain challenging for most. Health Aff (Millwood) 2014;33:1664-71.

58. Nakamura MM, Harper MB, Castro AV, Yu FB, Jha AK. Impact of the meaningful use incentive program on electronic health record adoption by US children's hospitals. J Am Med Inform Assoc 2015;22:390-8.

59. Hing EF, Yang NF, Jamoon EW. Adoption of Certified Electronic Health Record Systems and Electronic Information Sharing in Physician Offices: United States, 2013 and 2014. NCHS Data Brief 2016:1-8.

60. Jha AK. Meaningful use of electronic health records: the road ahead. JAMA 2010;304:1709-10.

61. Blumenthal D, Tavenner M. The "meaningful use" regulation for electronic health records. N Eng J Med 2010:363:504.

62. Grant RW, Wald JS, Schnipper JL, Gandhi TK, Poon EG, Orav EJ, et al. Practice-linked online personal health records for type 2 diabetes mellitus: a randomized controlled trial. Arch Intern Med 2008;168:1776-82.

63. Institute of Medicine (US) Committee on Quality of Health Care in America; Kohn LT, Corrigan JM, Donaldson MS, editors. To Err is Human: Building a Safer Health System. Washington (DC): National Academies Press (US); 2000.

64. Institute of Medicine (US) Committee on Quality of Health Care in America. Crossing the Quality Chasm: A New Health System for the 21st Century, Washington (DC): National Academies Press (US); 2001.

65. Stead WW, Searle JR, Fessler HE, Smith JW, Shortliffe EH. Biomedical informatics: changing what physicians need to know and how they learn. Acad Med 2011;86:429-34.

66. Miller BM, Moore DE, Stead WW, Balser JR. Beyond Flexner: a new model for continuous learning in the health professions. Acad Med 2010;85:266-72.

67. Institute of Medicine (US), National Academy of Engineering (US) Roundtable on Value \& Sci-
ence-Driven Health Care. Engineering a Learning Healthcare System; 2011.

68. McDonald KM, Matesic B, Contopoulos-Ioannidis DG, Lonhart J, Schmidt E, Pineda N, et al. Patient safety strategies targeted at diagnostic errors: a systematic review. Ann Intern Med 2013;158:381-9.

69. Schiff GD, Bates DW. Can electronic clinical documentation help prevent diagnostic errors? N Eng J Med 2010;362:1066-9.

70. Graber ML, Kissam S, Payne VL, Meyer AND, Sorensen A, Lenfestey N, et al. Cognitive interventions to reduce diagnostic error: a narrative review. BMJ Quality \& Safety 2012;21:535-57.

71. Singh H, Thomas EJ, Mani S, Sittig D, Arora H, Espadas D, et al. Timely follow-up of abnormal diagnostic imaging test results in an outpatient setting: are electronic medical records achieving their potential? Arch Intern Med 2009;169:1578-86.

72. Fleming NS, Culler SD, McCorkle R, Becker ER, Ballard DJ. The financial and nonfinancial costs of implementing electronic health records in primary care practices. Health Aff (Milwood) 2001;30:481-9

73. Rea S, Pathak J, Savova G, Oniki TA, Westberg $\mathrm{L}$, Beebe $\mathrm{CE}$, et al. Building a robust, scalable and standards-driven infrastructure for secondary use of EHR data: the SHARPn project. J Biomed Inform 2012;45;763-71.

74. Iezzoni LI. Assessing quality using administrative data. Ann Intern Med 1997;127:666-74.

75. Shortell SM, Rundall TG, Hsu J. Improving patient care by linking evidence-based medicine and evidence-based management. JAMA 2007;298:673-6.

76. Sim I, Gorman P, Greenes RA, Haynes RB, Kaplan B, Lehmann H, et al. Clinical decision support systems for the practice of evidence-based medicine. J Am Med Inform Assoc 2001;8:527-34.

77. Lowe HJ, Ferris TA, Hernandez PM, Weber SC. STRIDE--An integrated standards-based translational research informatics platform. Proc AMIA Annu Fall Symp 2009:391-5.

78. D'Avolio LW, Farwell WR, Fiore LD. Comparative effectiveness research and medical informatics, Am J Med 2010;123:e32-7.

79. Klann JG, Buck MD, Brown J, Hadley M, Elmore R, Weber GM, et al. Query Health: standards-based, cross-platform population health surveillance. J Am Med Inform Assoc 2014;21:650-6.

80. Frankovich J, Longhurst CA, Sutherland SM. Evidence-Based Medicine in the EMR Era. N Eng J Med 2011:365:1758-9.

81. Klann JG, Mendis M, Phillips LC, Goodson AP, Rocha BH, Goldberg HS, et al. Taking advantage of continuity of care documents to populate a research repository. J Am Med Inform Assoc 2015;22:370-9

82. Rasmussen LV, Kiefer RC, Mo H, Speltz P, Thompson WK, Jiang G, et al. A Modular Architecture for Electronic Health Record-Driven Phenotyping, AMIA Jt Summits Transl Sci Proc 2015:147-51.

83. Wright A, Sittig DF, Ash JS, Sharma S, Pang JE, Middleton B. Clinical decision support capabilities of commercially-available clinical information systems. J Am Med Inform Assoc;16:637-44.

84. Sittig DF, Wright A, Meltzer S, Simonaitis L, Evans RS, Nichol WP, et al. Comparison of clinical knowledge management capabilities of commer- 
cially-available and leading internally-developed electronic health records. BMC Med Inform Decis Mak 2011;11:13.

85. Boxwala AA, Kim J, Grillo JM, Ohno-Machado L. Using statistical and machine learning to help institutions detect suspicious access to electronic health records. J Am Med Inform Assoc 2011;18:498-505.

86. Jordan MI, Mitchell TM. Machine learning: Trends, perspectives, and prospects. Science 2015;349:255-60.

87. Wright A, McCoy A, Henkin S, Flaherty M, Sittig D. Validation of an association rule mining-based method to infer associations between medications and problems. Appl Clin Inform 2013;4:100-9.

88. Lee J, Maslove DM, Dubin JA. Personalized mortality prediction driven by electronic medical data and a patient similarity metric. PLoS One 2015;10:e0127428.

89. Jensen PB, Jensen LJ, Brunak S. Mining electronic health records: towards better research applications and clinical care. Nat Rev Genet 2012;13:395-405.

90. Simpao AF, Ahumada LM, Gálvez JA, Rehman MA. A review of analytics and clinical informatics in health care. J Med Syst 2014;38:45-7.

91. Natter MD, Quan J, Ortiz DM, Bousvaros A, Ilowite NT, Inman CJ, et al. An i2b2-based, generalizable, open source, self-scaling chronic disease registry, J Am Med Inform Assoc 2013;20:172-9.

92. Goldberg HS, Paterno MD, Rocha BH, Schaeffer M, Wright A, Erickson JL, et al. A highly scalable, interoperable clinical decision support service. J Am Med Inform Assoc 2014;21:e55-62.

93. Kawamoto K, Lobach DF. Proposal for fulfilling strategic objectives of the U.S. Roadmap for national action on clinical decision support through a service-oriented architecture leveraging HL7 services. J Am Med Inform Assoc 2007;14:146-55.

94. Wright A, Sittig DF, SANDS: A service-oriented architecture for clinical decision support in a National Health Information Network. J Biomed Inform 2008;41:962-81.

95. Ohno-Machado L. Big science, big data, and a big role for biomedical informatics. JAm Med Inform Assoc 2012;19:e1-e1.

96. Komaroff AL. The variability and inaccuracy of medical data. Proc IEEE 1979;67:1196-207.

97. Harrison MI, Koppel R, Bar-Lev S. Unintended consequences of information technologies in health care--an interactive sociotechnical analysis. J Am Med Inform Assoc 2007;14:542-9.

98. Ash JS, Sittig DF, Campbell EM, Guappone KP, Dykstra RH. Some unintended consequences of clinical decision support systems. Proc AMIA Annu Fall Symp 2007:26-30.

99. Ash JS, Berg M, Coiera E. Some unintended consequences of information technology in health care: the nature of patient care information system-related errors. J Am Med Inform Assoc 2004;11:104-12.

100. Crowe B. Association of Medical Directors of Information Systems consensus on inpatient electronic health record documentation, Appl Clin Inform 2013;4:293-303.

101. Kuhn T, Basch P, Barr M, Yackel T. Medical Informatics Committee of the American College of Physicians, Clinical documentation in the 21st century: executive summary of a policy position paper from the American College of Physicians. Ann Intern Med 2015;162:301-3.

102. Hirschtick RE. Copy-and-Paste. JAMA 2006; 295:2335-6.

103. Coiera E, Aarts J, Kulikowski C. The dangerous decade. J Am Med Inform Assoc 2012;19:2-5.

104. Chute C, Beck S, Fisk T. The Enterprise Data Trust at Mayo Clinic: a semantically integrated warehouse of biomedical data. J Am Med Inform Assoc 2010;17:131-5.

105. Einbinder JS, Bates DW. Leveraging information technology to improve quality and safety. Yearb Med Inform 2007:22-9.

106. Hoy MB. Personal Activity Trackers and the Quantified Self. Med Ref Serv Q 2016;35:94 100.

107. Swan M. Health 2050: The Realization of Personalized Medicine through Crowdsourcing, the Quantified Self, and the Participatory Biocitizen. J Pers Med 2012;2:93-118

108. Zai AH, Ronquillo JG, Nieves R, Chueh HC, Kvedar JC, Jethwani K. Assessing hospital readmission risk factors in heart failure patients enrolled in a telemonitoring program. Int $\mathrm{J}$ Telemed Appl 2013;2013:305819.

109. Clark RA, Inglis SC, McAlister FA, Cleland JGF, Stewart S. Telemonitoring or structured telephone support programmes for patients with chronic heart failure: systematic review and meta-analysis. BMJ 2007;334:942.

110. Barabási A-L. Network medicine--from obesity to the "diseasome". N Eng J Med 2007;357:404-7.

111. Ohmann C, Kuchinke W. Future developments of medical informatics from the viewpoint of networked clinical research. Interoperability and integration. Methods Inf Med 2009;48;45-54.

112. Yasnoff WA, Humphreys BL, Overhage JM, Detmer DE, Brennan PF, Morris RW, et al. A consensus action agenda for achieving the national health information infrastructure. J Am Med Inform Assoc 2004;11(4):332-8.

113. Walker J, Pan E, Johnston D, Adler-Milstein J, Bates DW, Middleton B. The value of health care information exchange and interoperability. Health Aff (Milwood) 2005 Suppl Web Exclusives W5-10-W5-18.

114. Dolin RH, Alschuler L, Beebe C, Biron PV, Boyer SL, Essin D, et al. The HL7 Clinical Document Architecture. JAm Med Inform Assoc 2001;8;552-69.

115. Weber GM. Federated queries of clinical data repositories: the sum of the parts does not equal the whole. J Am Med Inform Assoc 2013;20:e155-e161.

116. Mandl KD, Kohane IS. Federalist principles for healthcare data networks, Nature Publishing Group 2015;33:360-3.

117. Ferranti JM, Musser RC, Kawamoto K, Hammond WE. The clinical document architecture and the continuity of care record: a critical analysis. J Am Med Inform Assoc 2006;13:245-52.

118. Kawamoto K, Shields D, McIntyre A, Strasberg H. Evaluation of HL7 Continuity of Care Document as the Foundation for an International Virtual Medical Record Standard for Clinical Decision Support. (7AD). http://wiki.hl7.org/ images/d/d3/HL7vMR_CCD_Coverage_of_
CDS_Data_Needs_v2011-03-17.pdf (accessed March 3, 2015).

119. Johnson PD, Tu SW, Musen MA, Purves I. A virtual medical record for guideline-based decision support. Proc AMIA Symp 2001:294-8.

120. Marcos C, González-Ferrer A, Peleg M, Cavero C. Solving the interoperability challenge of a distributed complex patient guidance system: a data integrator based on HL7's Virtual Medical Record standard. J Am Med Inform Assoc 2015;22:587-99.

121. Ingram D, Beale T, Heard S, Kalra D, Lloyd D, Schloeffel P. Introducing OpenEHR. Openehr. org. http://www.openehr.org/releases/1.0/ openEHR/introducing_openEHR.pdf (accessed June 18, 2016).

122. Bender D, Sartipi K. HL7 FHIR: An Agile and RESTful approach to healthcare information exchange. In: 2013 IEEE 26th International Symposium on Computer-Based Medical Systems (CBMS). IEEE; 2013. p. 326-31.

123. Kasthurirathne SN, Mamlin B, Grieve G, Biondich P. Towards Standardized Patient Data Exchange: Integrating a FHIR Based API for the Open Medical Record System. Stud Health Technol Inform 2015;216:932.

124. HL7 launches Argonaut Project to advance FHIR interoperability standard. Health Manag Technol 2015;36:26

125. Sittig DF, Hazlehurst BL, Brown J, Murphy $\mathrm{S}$, Rosenman M, Tarczy-Hornoch P, et al. A survey of informatics platforms that enable distributed comparative effectiveness research using multi-institutional heterogenous clinical data. Medical Care 2012;50 Suppl:S49-59.

126. Kuperman GJ, Gardner RM, Pryor TA. Decision Support on the HELP System. In: Computer-Assisted Medical Decision Making. New York, NY: Springer; 1991. p. 53-67.

127. Perlin JB, Kolodner RM, Roswell RH. The Veterans Health Administration: quality, value, accountability, and information as transforming strategies for patient-centered care. Am J Manag Care 2004;10:828-36.

128. Shwe M, Sujansky W, Middleton B. Reuse of knowledge represented in the Arden syntax. Proc Annu Symp Comput Appl Med Care 1992:47-51.

129. Samwald M, Fehre K, de Bruin J, Adlassnig K-P. The Arden Syntax standard for clinical decision support: experiences and directions. J Biomed Inform 2012;45:711-8.

130. Pryor TA, Hripcsak G. The arden syntax for medical logic modules. Int J Clin Monit Comput 1993;10:215-24.

131. Sordo M, Boxwala AA, Ogunyemi O, Greenes RA. Description and status update on GELLO: a proposed standardized object-oriented expression language for clinical decision support. Stud Health Technol Inform 2004;107:164-8.

132. McDonald CJ, Huff SM, Suico JG, Hill G, Leavelle D, Aller R, et al. LOINC, a universal standard for identifying laboratory observations: a 5-year update. Clin Chem 2003:49:624-33.

133. Freimuth RR, Wix K, Zhu Q, Siska M, Chute CG Evaluation of RxNorm for Medication Clinical Decision Support. Proc AMIA Annu Fall Symp 2014(2014):554-63.

134. Boxwala AA, Peleg M, Tu S, Ogunyemi O, Zeng 
QT, Wang D, et al. GLIF3: a representation format for sharable computer-interpretable clinical practice guidelines. J Biomed Inform 2004:37:147-61.

135. Peleg M. Computer-interpretable clinical guidelines: a methodological review. J Biomed Inform 2013;46:744-63.

136. Fox J, Johns N, Lyons C, Rahmanzadeh A, Thomson R, Wilson P. PROforma: a general technology for clinical decision support systems. Comput Methods Programs Biomed 1997;54:59-67.

137. Shahar Y, Young O, Shalom E, Galperin M, Mayaffit A, Moskovitch R, et al. A framework for a distributed, hybrid, multiple-ontology clinical-guideline library, and automated guideline-support tools. J Biomed Inform 2004;37:325-44.

138. Kawamoto K, Lobach DF. Design, implementation, use, and preliminary evaluation of SEBASTIAN, a standards-based Web service for clinical decision support. Proc AMIA Annu Fall Symp 2005(2005):380-384.

139. Boxwala AA, Rocha BH, Maviglia S, Kashyap V, Meltzer S, Kim J, et al. A multi-layered framework for disseminating knowledge for computer-based decision support. J Am Med Inform Assoc 2011;18 Suppl 1:1132-9.

140. Tu SW, Campbel JR, Glasgow J, Nyman MA, McClure R, McClay J, et al. The SAGE Guideline Model: achievements and overview. J Am Med Inform Assoc 2007;14:589-98.

141. Greenes R, Bloomrosen M, Brown-Connolly NE, Curtis C, Detmer DE, Enberg R, et al. The morningside initiative: collaborative development of a knowledge repository to accelerate adoption of clinical decision support. Open Med Inform J 2010;4:278-90.

142. Peleg M, Tu S. Decision support, knowledge representation and management in medicine. Yearb Med Inform 2006:72-80.

143. The medical knowledge crisis and its solution through knowledge management. Openclinical. org. (n.d.). http://www.openclinical.org/docs/ whitepaper.pdf (accessed June 19, 2016).

144. Fox J, Gutenstein M, Khan O, South M, Thomson R. OpenClinical.net: A platform for creating and sharing knowledge and promoting best practice in healthcare. Computers in Industry 2015;66:63-72.

145. Arel I, Rose DC, Karnowski TP. Deep Machine Learning - A New Frontier in Artificial Intelligence Research [Research Frontier]. IEEE Computational Intelligence Magazine 2010;5:13-8.

146. Bellazzi R, Diomidous M, Sarkar IN, Takabayashi K, Ziegler A, McCray AT. Data analysis and data mining: current issues in biomedical informatics. Methods Inf Med 2011;50:536-44.

147. Collins FS, Feero WG, Guttmacher AE. Genomic medicine--an updated primer. N Eng J Med 2010;362:2001-11.

148. Weber GM, Mandl KD, Kohane IS. Finding the missing link for big biomedical data. JAMA 2014;311:2479-80.

149. Li C. Personalized medicine - the promised land: are we there yet? Clinical Genetics 2011;79:403-12.

150. Mirnezami R, Nicholson J, Darzi A. Preparing for Precision Medicine. N Eng J Med
2012;366:489-91.

151. Collins FS, Varmus H. A new initiative on precision medicine. N Eng J Med 2015;372:793-5.

152. Barnett GO, Cimino JJ, Hupp JA, Hoffer EP. DXplain. An evolving diagnostic decision-support system. JAMA 1987;258:67-74.

153. Petro J. Watson, I presume. Health Manag Technol 2012;33:8-11.

154. Vardell E, Moore M. Isabel, a clinical decision support system. Med Ref Serv Q 2011;30:158-66.

155. Gordon CL, Weng C. Combining expert knowledge and knowledge automatically acquired from electronic data sources for continued ontology evaluation and improvement. J Biomed Inform 2015;57:42-52.

156. Tu SW, Peleg M, Carini S, Bobak M, Ross J, Rubin D, et al. A practical method for transforming free-text eligibility criteria into computable criteria. J Biomed Inform 2011;44:239-50.

157. Shortliffe EH. Computer Programs to Support Clinical Decision Making. JAMA 1987;258:61-6.

158. Littlejohns P, Wyatt JC, Garvican L. Evaluating computerised health information systems: hard lessons still to be learnt. BMJ 2003;326:860-3.

159. Berner ES. Clinical Decision Support Systems: State of the Art; 2009. p. 1-26. http://JAMIAoxfordjournals.org.ezp-prodl.hul.harvard.edu/ (accessed March 3, 2015).

160. Wright A, DSittig DF, Ash JS, Sharma S, Pang JE, Middleton B. Clinical decision support capabilities of commercially-available clinical information systems. J Am Med Inform Assoc 2009;16:637-44.

161. Sittig DF, Wright A, Osheroff JA, Middleton B, Teich JM, Ash JS, et al. Grand challenges in clinical decision support. J Biomed Inform 2008:41:387-92.

162. Shiffman RN, Dixon J, Brandt C, Essaihi A, Hsiao A, Michel G, et al. The GuideLine Implementability Appraisal (GLIA): development of an instrument to identify obstacles to guideline implementation BMC Med Inform Decis Mak 2005;5:23.

163. Hajizadeh N, Kashyap N, Michel G, Shiffman RN. GEM at 10: a decade's experience with the Guideline Elements Model Proc AMIA Annu Fall Symp 2011 (2011):520-8.

164. Kong G, Xu D. Clinical decision support systems: a review on knowledge representation and inference under uncertainties. Int J Intel Comp Sys 2008;1;159-67.

165. Patel VL, Shortliffe EH, Stefanelli M, Szolovits P, Berthold MR, Bellazzi R, et al. The coming of age of artificial intelligence in medicine. Artif Intell Med 2009;46: 5-17.

166. Miller RA, Pople HE, Myers JD. Internist-1, an experimental computer-based diagnostic consultant for general internal medicine. N Eng J Med 1982;307:468-76.

167. Miller RA, McNeil MA, Challinor SM, Masarie FE, Myers JD. The INTERNIST-1/QUICK MEDICAL REFERENCE project--status report. West J Med 1986;145:816-22.

168. Worley WE. Meditel: Computer Assisted Diagnosis. Ann Intern Med 1990;112:154.

169. Berner ES, Webster GD, Shugerman AA, Jackson
JR, Algina J, Baker AL, et al. Performance of four computer-based diagnostic systems. N Eng J Med 1994;330:1792-6.

170. Ledley RS, Lusted LB. Reasoning foundations of medical diagnosis; symbolic logic, probability, and value theory aid our understanding of how physicians reason. Science 1959;130:9-21.

171. Szolovits P, Pauker SG. Categorical and probabilistic reasoning in medical diagnosis. Artificial Intelligence 1978;11:115-44.

172. Pauker SG, Kassirer JP. The threshold approach to clinical decision making. $\mathrm{N}$ Eng J Med 1980;302:1109-17.

173. Pauker SG, Gorry GA, Kassirer JP, Schwartz WB. Towards the simulation of clinical cognition. Taking a present illness by computer. Am J Med 1976;60:981-96.

174. De Dombal FT. Computer-aided decision support in acute abdominal pain, with special reference to the EC concerted action. Int J Biomed Comput 1990;26:183-8.

175. De Dombal FT. Computer-aided decision support in clinical medicine. Int J Biomed Comput 1989;24:9-16.

176. Shwe MA, Middleton B, Heckerman DE, Henrion M, Horvitz EJ, Lehmann HP, et al. Probabilistic diagnosis using a reformulation of the INTERNIST-1/QMR knowledge base. I. The probabilistic model and inference algorithms. Methods Inf Med 1991;30:241-55.

177. Middleton B, Shwe MA, Heckerman D, Henrion M, Horvitz E, Lehmann HP, et al. Probabilistic diagnosis using a reformulation of the INTERNIST-1/QMR knowledge base. Part II: Evaluation of Diagnostic Performance. Methods Inf Med 1991;4:256-67.

178. Pradhan M, Provan G, Middleton B, Henrion $\mathrm{M}$. Knowledge engineering for large belief networks; 1994. p. 484-90.

179. Van Allen EM, Wagle N, Levy MA. Clinical analysis and interpretation of cancer genome data. J Clin Oncol 2013;31:1825-33.

180. Mancinelli L, Cronin M, Sadee W. Pharmacogenomics: The promise of personalized medicine. AAPS PharmSci 2000;2:29-41.

181. Peterson JF, Bowton E, Field JR, Beller M, Mitchell J, Schildcrout J, et al. Electronic health record design and implementation for pharmacogenomics: a local perspective Genet Med 2013;15:833-41.

182. Pulley JM, Denny JC, Peterson JF, Bernard GR, Vnencak-Jones CL, Ramirez AH, et al. Operational implementation of prospective genotyping for personalized medicine: the design of the Vanderbilt PREDICT project. Clin Pharmacol Ther 2012;92:87-95.

183. Anderson JL, Horne BD, Stevens SM, Grove AS, Barton S, Nicholas ZP, et al. Randomized trial of genotype-guided versus standard warfarin dosing in patients initiating oral anticoagulation Circulation 2007;116:2563-70.

184. Robinson PN. Deep phenotyping for precision medicine. Hum Mutat 2012;33:777-80.

185. National Research Council (US) Committee on A Framework for Developing a New Taxonomy of Disease, Toward Precision Medicine: Building a Knowledge Network for Biomedical Research and a New Taxonomy of Disease. Washington 
(DC): National Academies Press (US); 2011.

186. Wright A, Sittig DF. A four-phase model of the evolution of clinical decision support architectures. Int J Med Inform 2008;77:641-9.

187. Warner HR, Toronto AF, Veasey LG, Stephenson R. A mathematical approach to medical diagnosis: application to congenital heart disease.1961. MD Comput 1992 Jan-Feb;9(1):43-50.

188. Bleich HL. Computer evaluation of acid-base disorders. Trans Assoc Am Physicians 1968;81:184-9.

189. Miller RA, Masarie FE. The demise of the "Greek Oracle" model for medical diagnostic systems. Methods Inf Med 1990;29:1-2.

190. Shortliffe EH, Axline SG, Buchanan BG, Merigan TC, Cohen SN. An artificial intelligence program to advise physicians regarding antimicrobial therapy. Comp Biomed Res 1973;6:544-60

191. Porter JF, Kingsland LC, Lindberg DA, Shah I, Benge JM, Hazelwood SE, et al. The AI/RHEUM knowledge-based computer consultant system in rheumatology. Performance in the diagnosis of 59 connective tissue disease patients from Japan. Arthritis Rheum 1988;31:219-26.

192. Meyer AND, Payne VL, Meeks DW, Rao R, Singh H. Physicians' diagnostic accuracy, confidence, and resource requests: a vignette study. JAMA Intern Med 2013;173:1952-8.

193. Kuperman GJ, Gardner RM. T.A. PRYOR, HELP: a dynamic hospital information system. Springer-Verlag; 1991.

194. Kuperman GJ, Spurr C, Flammini S, Bates D, Glaser J. A clinical information systems strategy for a large integrated delivery network. Proc AMIA Symp 2000:438-42.

195. Payne TH, Hoey PJ, Nichol P, Lovis C. Preparation and use of preconstructed orders, order sets, and order menus in a computerized provider order entry system. J Am Med Inform Assoc 2003;10:322-9.

196. Thompson TG, Brailer DJ. The Decade of Health Information Technology: Delivering Consumer-centric and Information-rich Health Care --Framework for Strategic Action. Washington, D.C.; 2004.

197. Seliger R. H17 CCOW - Clinical Context Object Workgroup. (Accessed Nov. 2, 2015). https:// en.wikipedia.org/wiki/CCOW.

198. Seliger R. Healthcare IT tipping point? Health Manag Technol 2005;26:48-7.

199. Hripcsak G, Ludemann P, Pryor TA, Wigertz OB, Clayton PD. Rationale for the Arden Syntax. Comp Biomed Res 1994;27:291-324.

200. Jenders RA, Hripcsak G, Sideli RV, DuMouchel $\mathrm{W}$, Zhang H, Cimino JJ, et al. Medical decision support: experience with implementing the Arden Syntax at the Columbia-Presbyterian Medical Center. Proc Annu Symp Comput Appl Med Care 1995:169-73.

201. Ram P, Berg D, Tu S, Mansfield G, Ye Q, Abarbanel R, et al. Executing clinical practice guidelines using the SAGE execution engine. Stud Health Technol Inform 2004;107:251-5.

202. Middleton B. The clinical decision support consortium. Stud Health Technol Inform 2009;150:26-30

203. Paterno MD, Maviglia SM, Ramelson HZ, Schaeffer M, Rocha BH, Hongsermeier T, et al.
Creating shareable decision support services: an interdisciplinary challenge. AMIA Annu Symp Proc 2010 Nov 13;2010:602-6..

204. Dixon BE, Simonaitis L, Goldberg HS, Paterno MD, Schaeffer M, Hongsermeier T, et al. A pilot study of distributed knowledge management and clinical decision support in the cloud. Artif Intell Med 2013;59:45-53.

205. Wright A, Sittig DF, Ash JS, Erickson JL, Hickman TT, Paterno M, et al. Lessons learned from implementing service-oriented clinical decision support at four sites: A qualitative study. Int J Med Inform 2015;84:901-11.

206. Goldberg HS, Paterno MD, Grundmeier RW, Rocha BH, Hoffman JM, Tham E, et al. Use of a remote clinical decision support service for a multicenter trial to implement prediction rules for children with minor blunt head trauma. Int J Med Inform 2016;87:101-10.

207. www.opencds.org. Opencds.org. http://www. opencds.org/ (accessed January 26, 2016).

208. Peleg M, Shahar Y, Quaglini S. Making Healthcare More Accessible, Better, Faster, and Cheaper: The MobiGuide Project. European Journal of ePractice 2013.

209. Quaglini S, Shahar Y, Peleg M, Miksch S, Napolitano C, Rigla M, et al. Supporting shared decision making within the MobiGuide project. AMIA Annu Symp Proc 2013 Nov 16;2013:1175-84.

210. Blobel B. Advanced and secure architectural EHR approaches, Int J Med Inform 2006;75:185-90.

211. Mandl KD, Kohane IS. Escaping the EHR trap--the future of health IT. N Eng J Med 2012;366:2240-2.

212. Mandl KD, Mandel JC, Murphy SN, Bernstam EV, Ramoni RL, Kreda DA, et al. The SMART Platform: early experience enabling substitutable applications for electronic health records. J Am Med Inform Assoc 2012;19;597-603.

213. Mandl KD, Mandel JC, Kohane IS. Driving Innovation in Health Systems through an Apps-Based Information Economy. Cell Syst 2015;1:8-13.

214. Wennberg JE. Unwarranted variations in healthcare delivery: implications for academic medical centres. BMJ 2002;325:961-4.

215. Westbrook JI, Coiera E, Dunsmuir WTM, Brown BM, Kelk N, Paoloni R, et al. The impact of interruptions on clinical task completion. Qual Saf Health Care 2010;19:284-9.

216. Coiera E. The science of interruption. BMJ Qual Saf 2012;21:357-60.

217. Wears RL, Berg M. Computer Technology and Clinical Work: Still Waiting for Godot. JAMA 2005;293:1261-3.

218. Slight SP, Seger DL, Nanji KC, Cho I, Maniam $\mathrm{N}$. Are we heeding the warning signs? Examining providers' overrides of computerized drug-drug interaction alerts in primary care. PLoS One 2013 Dec 26;8(12):e85071

219. Nanji KC, Slight SP, Seger DL, Cho I, Fiskio JM, Redden LM, et al. Overrides of medication-related clinical decision support alerts in outpatients. J Am Med Inform Assoc 2014;21:487-91.

220. Bryant AD, Fletcher GS, Payne TH. Drug interaction alert override rates in the Meaningful Use era: no evidence of progress. Appl Clin Inform
2014;5:802-13.

221. McDonald CJ. Protocol-based computer reminders, the quality of care and the non-perfectability of man. N Eng J Med 1976;295:1351-5.

222. Kuperman GJ, Bobb A, Payne TH, Avery AJ, Gandhi TK, Burns G, et al. Medication-related Clinical Decision Support in Computerized Provider Order Entry Systems: A Review. J Am Med Inform Assoc 2007;14:29-40.

223. Maviglia SM, Yoon CS, Bates DW, Kuperman G. KnowledgeLink: impact of context-sensitive information retrieval on clinicians' information needs. J Am Med Inform Assoc 2006;13:67-73.

224. Del Fiol G, Huser V, Strasberg HR, Maviglia SM, Curtis C, Cimino JJ. Implementations of the HL7 Context-Aware Knowledge Retrieval ("Infobutton") Standard: challenges, strengths, limitations, and uptake. J Biomed Inform 2012;45:726-35.

225. Cimino JJ, Li J. Sharing infobuttons to resolve clinicians' information needs. Proc AMIA Annu Fall Symp 2003:815.

226. Wright A, Sittig DF, Carpenter JD, Krall MA, Pang JE, Middleton B. Order sets in computerized physician order entry systems: an analysis of seven sites. Proc AMIA Annu Fall Symp 2010 (2010):892-6.

227. Wright A, Feblowitz JC, Pang JE, Carpenter JD, Krall MA, Middleton B, et al. Use of order sets in inpatient computerized provider order entry systems: a comparative analysis of usage patterns at seven sites. Int J Med Inform 2012;81:733-45.

228. Zhou L, Gurjar R, Regier R, Morgan S, Meyer $\mathrm{T}$, Aroy T, et al. A study on design and development of enterprise-wide concepts for clinical documentation templates. Proc AMIA Annu Fall Symp 2008:1193.

229. Whipple NN, Palchuk MB, Olsha-Yehiav M, Li Q, Middleton B. Supporting CMT and user customization in Clinical Documentation templates. Proc AMIA Annu Fall Symp 2007:1153.

230. Payne TH, Perkins M, Kalus R, Reilly D. The transition to electronic documentation on a teaching hospital medical service. Proc AMIA Annu Fall Symp 2006(2006):629-33.

231. Lin HS, Stead WW. Computational Technology for Effective Health Care: Immediate Steps and Strategic Directions. Washington DC: National Academies Press; 2009.

232. Sittig DF, Wright A, Simonaitis L, Carpenter JD, Allen GO, Doebbeling BN, et al. The state of the art in clinical knowledge management: an inventory of tools and techniques. Int J Med Inform 2010;79:44-57.

233. Glaser J, Hongsermeier T. Managing the Investment in Clinical Decision Support. In: Clinical Decision Support. Elsevier; 2014. p. 665-88.

234. Goldman DS, Colecchi J, Hongsermeier TM, Maviglia SM. Knowledge management and content integration: a collaborative approach. Proc AMIA Annu Fall Symp (2008):953.

235. Zozus M, Hammond WE, Green BB, Kahn MG, Richesson RL, Rusincovitch SA, et al. Data Quality Assessment Recommendations for Secondary use of EHR Data; 2015.

236. Cusack CM, Hripcsak G, Bloomrosen M, Rosenbloom ST, Weaver CA, Wright A, et al. The future state of clinical data capture and documentation: 
a report from AMIA's 2011 Policy Meeting. J Am Med Inform Assoc 2013;20:134-40.

237. Rogers EM. Diffusion of Innovations, 4th Edition; 2010

238. Liu JLY, Wyatt JC. The case for randomized controlled trials to assess the impact of clinical information systems. J Am Med Inform Assoc 2011;18:173-80.

239. Kaplan B. Evaluating informatics applicationsclinical decision support systems literature review. Int J Med Inform 2001;64:15-37.

240. Friedman CP. A "fundamental theorem" of biomedical informatics. J Am Med Inform Assoc 2009;16:169-70.

241. Swenson CJ, Appel A, Sheehan M, Hammer A, Fenner Z, Phibbs S, et al. Using information technology to improve adult immunization delivery in an integrated urban health system. Jt Comm J Qual Patient Saf 2012 Jan;38(1):15-23.

242. Nagykaldi Z, Aspy CB, Chou A, Mold JW. Impact of a Wellness Portal on the delivery of patient-centered preventive care. J Am Board Fam Med 2012;25:158-67.

243. Chou AF, Nagykaldi Z, Aspy CB, Mold JW. Promoting Patient-Centered Preventive Care Using a Wellness Portal: Preliminary Findings. J Prim Care Community Health 2010;1:88-92.

244. Lorenzi NM, Kouroubali A, Detmer DE, Bloomrosen M. How to successfully select and implement electronic health records (EHR) in small ambulatory practice settings. BMC Med Inform Decis Mak 2009;9:15.

245. Middleton B, Anderson J, Fletcher J, Masarie FE, Leavitt MK. Use of the WWW for distributed knowledge engineering for an EMR: the KnowledgeBank concept. Proc AMIA Symp 1998;126-30.

246. Wright A, Bates DW, Middleton B, Hongsermeier T, Kashyap V, Thomas SM, et al. Creating and sharing clinical decision support content with Web 2.0: Issues and examples. J Biomed Inform 2009;42:334-46.

247. Wegner DM, Ward AF. How Google is changing your brain. Sci Am 2013;309(6):58-61.

248. Tang H, Ng JHK. Googling for a diagnosis--use of Google as a diagnostic aid: internet based study. BMJ 2006;333;1143-5.

249. Fischer B. The End of Expertise. HBR.org; 2015. https://hbr.org/2015/10/the-end-of-expertise (accessed October 25, 2015).

250. Kohane IS. Using electronic health records to drive discovery in disease genomics. Nat Rev Genet 2011;12:417-28.

251. Littman BH, Marincola FM. Create a translational medicine knowledge repository--research downsizing, mergers and increased outsourcing have reduced the depth of in-house translational medicine expertise and institutional memory at many pharmaceutical and biotech companies: how will they avoid relearning old lessons? J Transl Med 2011;9:56.

252. Van Mulligen EM, Van Der Eijk C, Kors JA, Schijvenaars BJA, Mons B. Research for research: tools for knowledge discovery and visualization. Proc AMIA Symp 2002:835-9.

253. Sahoo SS, Nguyen V, Bodenreider O, Parikh P, Minning T, Sheth AP. A unified framework for managing provenance information in translational research. BMC Bioinformatics 2011;12:461.

254. Daniel C, Choquet R. Information technology for clinical, translational and comparative effectiveness research. Findings from the section clinical research informatics Yearb Med Inform. 2014;9:224-7.

255. Kawamoto K, Lobach DF, Willard HF, Ginsburg GS. A national clinical decision support infrastructure to enable the widespread and consistent practice of genomic and personalized medicine, BMC Med Inform Decis Mak 2009;9:17.

256. Kawamoto K, Hongsermeier T, Wright A, Lewis J, Bell DS, Middleton B. Key principles for a national clinical decision support knowledge sharing framework: synthesis of insights from leading subject matter experts. J Am Med Inform Assoc 2013;20:199-207.

257. Phansalkar S, Desai A, Choksi A, Yoshida E, Doole J, Czochanski M, et al. Criteria for assessing high-priority drug-drug interactions for clinical decision support in electronic health records. BMC Med Inform Decis Mak 2013;13:65.

258. Kohane IS, Masys DR, Altman RB. The incidentalome: a threat to genomic medicine. JAMA 206;296:212-5.

259. Blois MS. Clinical judgment and computers, $\mathrm{N}$ Eng J Med 1980;303:192-7.
260. Légaré F, Witteman HO. Shared decision making: examining key elements and barriers to adoption into routine clinical practice, Health Aff (Millwood) 2013;32:276-84.

261. Green ED, Guyer MS. National Human Genome Research Institute, Charting a course for genomic medicine from base pairs to bedside. Nature 2011;470:204-13.

262. Sander C. Genomic Medicine and the Future of Health Care. Science 2000;287:1977-8.

263. Kaelber DC, Jha AK, Johnston D, Middleton B, Bates DW. A Research Agenda for Personal Health Records (PHRs). J Am Med Inform Assoc 2008;15:729-36.

264. Hamburg MA, Collins FS. The Path to Personalized Medicine. N Eng J Med 2010;363:301-4.

265. Eddy DM, Schlessinger L. Methods for Building and Validating Equations for Physiology-Based Mathematical Models: Glucose Metabolism and Type 2 Diabetes in the Archimedes Model, Med Decis Making. (2015).

266. David Eddy Created The Archimedes Model To Predict And Analyze Care. Health Aff(Milwood) 2012;31:2451-2.

267. Musen MA. Dimensions of knowledge sharing and reuse. Comp Biomed Res 1992;25:435-67.

268. Finkelstein JB. Translational Research Going Mainstream. JNCI J Natl Cancer Inst 2008;100:1430-1.

269. PPayne PRO, Embi PJ, Niland J. Foundational biomedical informatics research in the clinical and translational science era: a call to action. J Am Med Inform Assoc 2010;17:615-6.

270. Szalma S, Koka V, Khasanova T, Perakslis ED. Effective knowledge management in translational medicine. JTransl Med 2010;8:68.

271. Sarkar IN. Biomedical informatics and translational medicine. J Transl Med 2010;8:22.

272. Mandl KD, Kohane IS. Time for a Patient-Driven Health Information Economy? N Eng J Med 2016;374:205-8.

\section{Correspondence to:}

Blackford Middleton

Cell: + 16173357098

E-Mail:bmiddlet@hsph.harvard.edu 